\title{
The Prevalence of Primary and Secondary Hyperparathyroidism and its Cardiometabolic Implications in Patients with Primary Aldosteronism.
}

Marta Araujo-Castro ( $D$ martaazul.2a@hotmail.com )

Hospital Universitario Ramon y Cajal https://orcid.org/0000-0002-0519-0072

Eider PASCUAL-CORRALES

Hospital Ramón y Cajal

María Fernández-Argueso

Ramon y Cajal University Hospital: Hospital Universitario Ramon y Cajal

Nuria Bengoa Rojano

Ramon y Cajal University Hospital: Hospital Universitario Ramon y Cajal

Ana García Cano

Ramon y Cajal University Hospital: Hospital Universitario Ramon y Cajal

Lucía Jiménez Mendiguchía

Ramon y Cajal University Hospital: Hospital Universitario Ramon y Cajal

Martín CUESTA

Hospital Clinico Universitario San Carlos

\section{Research Article}

Keywords: Primary aldosteronism, primary hyperparathyroidism, secondary hyperparathyroidism, cardiometabolic profile.

Posted Date: October 25th, 2021

DOI: https://doi.org/10.21203/rs.3.rs-1003319/v1

License: (a) This work is licensed under a Creative Commons Attribution 4.0 International License. Read Full License 


\section{Abstract}

Purpose: To analyze the prevalence of primary and secondary hyperparathyroidism in patients with primary aldosteronism (PA), and its implication on cardiovascular and metabolic outcomes.

Methods: A retrospective study of patients with PA (exposed cohort, $n=44$ ) and all essential hypertensive (EH) patients with adrenal lesions without PA nor other adrenal hypersecretion (non-exposed cohort, $\mathrm{n}=41$ ) on follow-up at our center between 2016 and 2020.

Results: The mean age of patients with PA and $\mathrm{EH}$ was $55.1 \pm 14.13$ and $66.3 \pm 10.93(\mathrm{P}<0.001)$, and $50 \%$ of $\mathrm{PA}$ and $39.0 \%$ of $\mathrm{EH}$ were women $(\mathrm{P}=0.309)$. At diagnosis, the prevalence of primary hyperparathyroidism in PA was of $18.2 \%$, and all were normocalcemic hyperparathyroidism cases. Globally, no differences were found in the prevalence of primary hyperparathyroidism compared to EH (18.2\% vs $29.3 \%, P=0.229)$ but hypercalcemic primary hyperparathyroidism was significantly more prevalent in $\mathrm{EH}$ patients than in PA $(22.0 \%$ vs $0 \%, P=0.001)$. There were $47.7 \%(n=21)$ cases of secondary hyperparathyroidism in patients with PA (4 due to CKD and vitamin D deficiency and 17 due to vitamin $D$ deficiency alone).

The cardiometabolic profile of patients with PA and hyperparathyroidism $(n=29)$ was similar to of those patients without hyperparathyroidism $(n=15)$ at diagnosis and after a median follow-up of 3.6 years [IQR 1.1-5.9].

Conclusions: Although primary and secondary hyperparathyroidism are common in patients with PA, their prevalence was similar than the observed in EH patients. Primary hyperparathyroidism is usually mild in PA, presenting as normocalcemic forms. No negative implications of the hyperparathyroidism in the cardiometabolic profile of PA were observed.

\section{Introduction}

Primary aldosteronism (PA) represents the commonest cause of endocrine hypertension [1]. Primary hyperparathyroidism is also a recognized cause of secondary hypertension [2]. Growing evidence suggests a bidirectional link between parathyroid hormone and aldosterone [3]. This relation could be in part explained for the regulatory action of intact parathyroid hormone (iPTH) on the zona glomerulosa of the adrenal glands as it was observed that IPTH stimulated aldosterone secretion in a dose dependent manner [4]. This finding is supported by the fact that several studies reported a decrease of aldosterone levels [5][6], and even resolution of aldosteronism [7], after parathyroidectomy.

Both, inappropriate aldosterone and $\mathrm{PTTH}$ secretion, are linked with development and progression of cardiovascular disease [8]. Secondary hyperparathyroidism is also associated with an increased cardiometabolic risk [9][10]. Thus, it would be expected that the combined secretion of aldosterone and iPTH would aggravate cardiovascular morbidity and mortality in patients with PA. However, few studies have evaluated this association [11-15] and the results about the improvement of the associated 
cardiovascular morbidity after parathyroidectomy are controversial, and some studies did not observe any improvement [14][15]. Moreover, to the best of our knowledge no previous study has compared the prevalence and incidence of hyperparathyroidism in PA and essential hypertensive patients.

The purpose of this retrospective cohort study was to evaluate prevalence of primary and secondary hyperparathyroidism in patients with PA, its evolution after the initiation of PA treatment, and its possible implication on cardiovascular outcomes. Moreover, the prevalence of hyperparathyroidism in patients with PA was compared with the prevalence in essential hypertensive $(\mathrm{EH})$ patients.

\section{Methods}

\section{Patients.}

For the selection of the PA cohort, all patients with a confirmed diagnosis of PA with available information on phospo-calcium metabolism who are in follow-up at the Ramón y Cajal Hospital (RCUH) between October 2018 and August 2020 were included in this study. PA patients were identified in two ways: 1) an electronic search through the admissions service (keywords: hyperaldosteronism, aldosteronism) and 2) electronic review through the Biochemistry service looking for all pathological aldosterone/renin ratios performed in these period (of the 1078 ratios performed, 116 were pathological, and only 27 of them correspond to patients who meet the criteria of PA definition). A total of 64 patients with PA were identified after excluding duplicate values. Only patients with available information in serum calcium, iPTH and serum 25-OH vitamin D were included $(n=44)$. The non-exposed cohort (hypertensive patients with adrenal incidentalomas in whom PA have been ruled out based on a normal plasma aldosterone concentration (PAC)/ plasma renin activity (PRA) or PAC/plasma renin concentration (PRC)) was extracted of the Ramón y Cajal ADRENAL INCIDENTALOMA register $(n=730)$. Patients with overt functionality syndromes (overt Cushing syndrome, PA and pheochromocytoma) $(n=13)$, adrenal carcinoma $(n=1)$ and confirmed autonomous cortisol secretion (cortisol dexamethasone suppression test $>5.0 \mu \mathrm{g} / \mathrm{dL}$ without specific data of Cushing's syndrome) ( $\mathrm{n}=38)$ were excluded. Only EH patients with available hormonal study (at least dexamethasone suppression test, urinary fractionated metanephrines and PAC and PRC or PRA) and phospo-calcium metabolism followed at our center in a similar period (2016-2020) were included $(n=41)$. This study was approved by the local ethics committee of the RCUH (Approval date: 29th May 2020).

\section{Clinical evaluation}

Medical records were reviewed and information about demographic factors (age and sex), comorbidities (hypertension, type II diabetes mellitus, obesity, dyslipidemia, chronic kidney disease (CKD) and cardiovascular and cerebrovascular diseases), was collected. In addition, data about medical treatment with antihypertensive, oral antidiabetic, lipid-lowering medications, insulin and calcium and vitamin D supplements were included in the aldosteronism and adrenal incidentaloma databases. Regarding physical evaluation, information about office systolic (SBP) and office diastolic blood pressure (DBP), 
and body mass index $\left(\mathrm{BMI}\left(\mathrm{kg} / \mathrm{m}^{2}\right)\right.$ were included. All these variables were collected at the diagnosis and at the last visit to our unit.

The definitions of chronic kidney disease (CKD), cardiovascular disease, cerebrovascular disease were the same as we previously published [16]. Type 2 diabetes mellitus, hypertension and dyslipidemia were defined according to the current clinical guidelines [17][18]. PA was diagnosed based on positive case detection of PAC/PRA ratio $>20 \mathrm{ng} / \mathrm{dL} / \mathrm{h}$ or PAC/PRC ratio $>1.8 \mu \mathrm{Ul} / \mathrm{mL}$, with a PAC $>15 \mathrm{ng} / \mathrm{dl}$ and at least one positive result from a confirmatory test $(n=16)$ (all patients underwent a saline infusion test except one patient who underwent a captopril test), except in patients with spontaneous hypokalemia, plasma renin below detection levels plus PAC $>20 \mathrm{ng} / \mathrm{dL}(\mathrm{n}=28)$ [19]. Renin and aldosterone determinations were performed after the withdrawal of antihypertensive drugs that might interfere with the results and with oral potassium supplementation if serum potassium was $<3.5 \mathrm{mEq} / \mathrm{L}$. Adrenal vein sampling (with cosyntropin stimulation) was performed in 15 patients with a successful sampling in 6 of them (selectivity index $>3$ in both adrenal veins) and 3 had bilateral disease and 3 unilateral.

Norcholesterol scintigraphy was available in 18 patients (including 6 of the patients with adrenal vein sampling), in 9 was suggestive of bilaterality, in 6 unilaterality and in 5 no evidence of hyper-uptake was observed. Biochemical cure of PA was defined as normalization of the PAC/PRA or PAC/PRC after adrenalectomy, and hypertension cure as normalization of blood pressure after adrenalectomy without antihypertensive medical treatment.

Primary hypercalcemic hyperparathyroidism was diagnosed if iPTH levels were $>65 \mathrm{pg} / \mathrm{mL}$ with serum protein-corrected calcium $>10.3 \mathrm{mg} / \mathrm{dl}$ [20]. Scintigraphy with SESTAMIBI was performed in these patients. Normocalcaemic primary hyperparathyroidism diagnosis was established when iPTH were $>65$ $\mathrm{pg} / \mathrm{mL}$ with normal serum protein-corrected calcium and after the exclusion of secondary causes of hyperparathyroidism [21]. Secondary hyperparathyroidism was diagnosed if iPTH levels were $>65 \mathrm{pg} / \mathrm{mL}$ with normal protein-corrected serum calcium and a secondary cause was identified (vitamin D deficiency, CKD, low calcium intake or intestinal malabsorption). Vitamin D insufficiency and deficiency were defined as a serum $25-\mathrm{OH}$ vitamin D below 30 and $10 \mathrm{ng} / \mathrm{ml}$., respectively

\section{Laboratory test and assays}

Data has been collected on fasting plasma glucose, glycated haemoglobin (HbA1c), total cholesterol, HDL-C, LDL-c, triglycerides, serum creatinine, glomerular filtration rate (GFR) (MDRD-4), sodium, potassium, calcium, and phosphorus, iPTH and $250 \mathrm{H}$-vitamin $\mathrm{D}$ at diagnosis into our unit and in the last available visit.

PAC was measured by the generation of angiotensin I in vitro, using a radioimmunoassay (Beckman Coulter). The mean intraassay and inter-assay coefficients of variation (CV) were $<11.3 \%$ and $\leq 20,9 \%$ respectively with a least detectable activity of $0.20 \mathrm{ng} / \mathrm{dL} / \mathrm{h}$. Since October 2018, PAC and PRC were measured using a chemiluminescence immunoassay (LIAISON assay from Diasorin) with an intraassay coefficient of variation of $<20 \%$ and a least detectable concentration of $1,91 \mathrm{ng} / \mathrm{dL}$ for aldosterone and between 1,6 to $1.96 \mu \mathrm{UI} / \mathrm{mL}$ for renin. Serum $250 \mathrm{H}$-Vitamin D was measured by chemiluminiscence 
immunoassay Architect i2000 (Abbott) with an intra-serial and intra-laboratory CV of $<10 \%$ and reference range of 20-80 ng/mL. iPTH, was measured by Cobas e411 (Roche) electrochemiluminescence immunoassay with an intra-serial and intra-laboratory CV of $<20 \%$ and reference range of $12-65 \mathrm{pg} / \mathrm{mL}$.

\section{Statistical analysis}

The analysis was performed with STATA 15. Data for continuous variables were expressed as mean \pm standard deviation (SD) or median and (range) and as percentages (and absolute values) for categorical variables. Normality was tested using the Shapiro-Wilk normality test and homogeneity of variances using the Levene's test. The Student $t$ test was used for quantitative variables and the $X^{2}$ test for qualitative variables. The odds ratio (OR) for qualitative variables was calculated using logistic regression; and the $\triangle$ coefficient with linear regression models. Multivariate logistic regression model was used for the calculation of adjusted OR by different potential confounders. Hazard ratios (HR) and $95 \% \mathrm{Cl}$ through follow-up were calculated from Cox regression analyses. The level of $\mathrm{P}<0.05$ or an $\mathrm{Cl}$ not included 1.0 were considered statistically significant.

\section{Results}

\section{Baseline characteristics}

44 patients with PA and $41 \mathrm{EH}$ patients were enrolled in the study. As expected, patients with PA presented a higher prevalence of hypokalemia and higher levels of PAC than essential hypertensive patients (Table 1). The prevalence of CKD was higher in patients with $\mathrm{EH}$, but these differences disappeared after adjusted by age (adjusted $\mathrm{OR}=3.4,95 \% \mathrm{Cl}=1.01-11.40$ ). In the same way, no differences in the cardiometabolic profile were observed even after adjusted by age. 
Table 1

Differential phenotypes between primary aldosteronism patients and essential hypertensive patients at diagnosis

\begin{tabular}{|c|c|c|c|}
\hline & $\begin{array}{l}\text { Primary aldosteronism } \\
(\mathrm{n}=44)\end{array}$ & $\begin{array}{l}\text { Essential hypertensive } \\
(n=41)\end{array}$ & $P$ value \\
\hline Age (years) & $55.1 \pm 14.13$ & $66.3 \pm 10.93$ & $<0.0001$ \\
\hline Female sex & $50 \%(n=22)$ & $39.0 \%(n=16)$ & 0.309 \\
\hline $\begin{array}{l}\text { Number of } \\
\text { antihypertensives }\end{array}$ & $2.5 \pm 1.21$ & $1.9 \pm 1.20$ & 0.042 \\
\hline Type 2 diabetes & $18.2 \%(n=8)$ & $36.6 \%(n=15)$ & 0.056 \\
\hline Dyslipidemia & $43.2 \%(n=19)$ & $63.4 \%(n=26)$ & 0.062 \\
\hline Cardiovascular events & $23.3 \%(n=10)$ & $22.0 \%(n=9)$ & 0.886 \\
\hline Cerebrovascular events & $2.3 \%(n=1)$ & $9.8 \%(n=4)$ & 0.150 \\
\hline Chronic kidney disease & $11.6 \%(n=5)$ & $35.0 \%(n=14)$ & 0.011 \\
\hline Hypokalemia & $37.2 \%(n=16)$ & $2.6 \%(n=1)$ & 0.0001 \\
\hline Obesity & $44.7 \%(n=17)$ & $57.1 \%(n=20)$ & 0.290 \\
\hline Primary HPT & $18.2 \%(n=8)$ & $29.3 \%(n=12)$ & 0.229 \\
\hline Secondary HPT & $47.7 \%(n=21)$ & $48.8 \%(n=20)$ & 0.923 \\
\hline Vitamin D deficiency & $75.0 \%(n=33)$ & $68.3 \%(n=28)$ & 0.492 \\
\hline $\mathrm{SBP}(\mathrm{mmHg})$ & $141.3 \pm 20.35$ & $136.0 \pm 13.58$ & 0.175 \\
\hline $\mathrm{DBP}(\mathrm{mmHg})$ & $84.0 \pm 10.28$ & $78.1 \pm 11.15$ & 0.018 \\
\hline BMI (kg/m2) & $30.0 \pm 7.65$ & $32.0 \pm 6.48$ & 0.261 \\
\hline GFR (MDRD-4) & $85.0 \pm 24.48$ & $65.6 \pm 21.49$ & $<0.001$ \\
\hline Serum potassium (mEq/L) & $3.6 \pm 0.61$ & $4.4 \pm 0.44$ & $<0.001$ \\
\hline Serum sodium (mEq/L) & $141.7 \pm 2.45$ & $141.0 \pm 1.80$ & 0.128 \\
\hline Serum calcium (mg/dl) & $9.3 \pm 0.48$ & $9.8 \pm 0.60$ & $<0.001$ \\
\hline Serum phosphorus & $3.3 \pm 0.71$ & $3.3 \pm 0.64$ & 0.982 \\
\hline Serum iPTH (ng/dL) & $81.6 \pm 31.23$ & $96.7 \pm 58.31$ & 0.137 \\
\hline $250 \mathrm{OH}$ Vitamin D (ng/dL) & $25.0 \pm 15.49$ & $26.2 \pm 15.27$ & 0.718 \\
\hline PAC (ng/dL) & $37.1 \pm 21.54$ & $14.5 \pm 10.48$ & $<0.0001$ \\
\hline
\end{tabular}


Primary aldosteronism

$(n=44)$
Essential hypertensive $(n=41)$
$P$ value

$3.28 \pm 4.03$

0.012

PRA (ng/dL/h)

$0.6 \pm 0.52$

$3.28 \pm 4.03$

ACS= autonomous cortisol secretion; GFR= glomerular filtration rate; NFAl= non-functioning adrenal incidentaloma; $\mathrm{PAC}=$ plasma aldosterone concentration; $\mathrm{PRA}=$ plasma renin activity

The prevalence of primary hyperparathyroidism in patients with PA was of $18.2 \%$, and all patients had normocalcemic hyperparathyroidism. There were $47.7 \%(n=21)$ cases of secondary hyperparathyroidism. Of the 21 patients with secondary HPT, 4 presented CKD and vitamin D deficiency and 17 vitamin D deficiency alone. No differences in the prevalence of primary and secondary hyperparathyroidism were found between PA and essential hypertensive (Table 1). Serum calcium levels were higher in patients with EH than PA. This could be explained by the higher prevalence of hypercalcemic hyperparathyroidism in patients with $\mathrm{EH}(22.0 \%$ vs $0 \%, \mathrm{P}=0.001)$.

\section{The evolution of the hyperparathyroidism after primary aldosteronism treatment}

Ten PA patients underwent unilateral adrenalectomy and 34 were treated with antihypertensive drugs (19 with spironolactone alone or in combination, 9 eplerenone alone or in combination and 3 patients with other antihypertensive drugs). Biochemical and hypertension cure were achieved in $100 \%$ and $30 \%$ of the patients underwent adrenalectomy, respectively. Patients with vitamin D deficiency $(n=33)$ and in 3 patients with normocalcemic hyperparathyroidism were under treatment with vitamin $D$ supplements at diagnosis of PA or they were initiated after PA diagnosis. After a median follow-up of 3.6 years [IQR 1.15.9] years, no new cases of primary hyperparathyroidism were detected, but 4 cases of secondary hyperparathyroidism were diagnosed (3 cases secondary to CKD and one due to vitamin deficiency). On the other hand, in 2 of the 8 patients with primary normocalcemic hyperparathyroidism, PTH levels normalized after vitamin $\mathrm{D}$ treatment, in 2 persisted, 3 were finally attribute to kidney function deterioration and one to vitamin $\mathrm{D}$ deficiency.

250H-Vitamin D improved in patients with PA who underwent adrenalectomy and worsened in those medically treated $(6.6 \pm 9.18 \mathrm{vs}-2.5 \pm 7.69 \mathrm{ng} / \mathrm{ml}, \mathrm{P}=0.006)$, while serum phosphorus levels tended to decrease more in operated PA $(-0.2 \pm 0.32 \mathrm{vs} 0.1 \pm 0.29 \mathrm{mg} / \mathrm{dL}, \mathrm{P}=0.043)$. No differences in other parameters of phospho-calcium metabolism were detected according to PA treatment. (Table 2). 
Table 2

Changes in blood pressure, biochemical and hormonal results over time in patients after adrenalectomy and those on medical treatment.

\begin{tabular}{|c|c|c|c|}
\hline & Adrenalectomy $(n=10)$ & Medical treatment $(n=34)$ & $P$ value \\
\hline$\Delta \mathrm{SBP}(\mathrm{mmHg})$ & $0.0 \pm 34.93$ & $-5.1 \pm 16.75$ & 0.603 \\
\hline$\Delta \mathrm{DBP}(\mathrm{mmHg})$ & $5.3 \pm 3.27$ & $-2.2 \pm 9.73$ & 0.075 \\
\hline$\Delta$ antihypertensive drugs & $-1.7 \pm 1.53$ & $0.5 \pm 1.08$ & 0.004 \\
\hline$\Delta$ Glucose $(\mathrm{mg} / \mathrm{dl})$ & $2.5 \pm 5.48$ & $3.0 \pm 19.33$ & 0.943 \\
\hline$\Delta$ GFR (MDRD-4) & $-26.5 \pm 36.72$ & $-14.5 \pm 12.58$ & 0.135 \\
\hline$\Delta$ Serum sodium $(\mathrm{mEq} / \mathrm{L})$ & $-2.9 \pm 2.75$ & $-0.6 \pm 2.66$ & 0.042 \\
\hline$\Delta$ Serum potassium $(\mathrm{mEq} / \mathrm{L})$ & $0.9 \pm 1.12$ & $0.5 \pm 0.77$ & 0.283 \\
\hline$\Delta$ Serum calcium $(\mathrm{mg} / \mathrm{dl})$ & $0.0 \pm 0.40$ & $0.0 \pm 0.27$ & 0.997 \\
\hline$\Delta$ Serum phosphorus $(\mathrm{mg} / \mathrm{dl})$ & $-0.2 \pm 0.32$ & $0.1 \pm 0.29$ & 0.043 \\
\hline$\Delta$ Serum PTH (ng/dL) & $-7.9 \pm 35.50$ & $-8.5 \pm 19.94$ & 0.958 \\
\hline$\Delta 250 \mathrm{H}$ Vitamin $\mathrm{D}(\mathrm{ng} / \mathrm{mL})$ & $6.6 \pm 9.18$ & $-2.5 \pm 7.69$ & 0.006 \\
\hline$\Delta \mathrm{LDL}-\mathrm{c}(\mathrm{mg} / \mathrm{dl})^{\star}$ & $11.4 \pm 24.03$ & $-10.1 \pm 46.19$ & 0.227 \\
\hline$\Delta \mathrm{HDL}-\mathrm{c}(\mathrm{mg} / \mathrm{dl})$ & $-3.7 \pm 4.96$ & $0.5 \pm 9.61$ & 0.280 \\
\hline$\Delta$ Triglycerides $(\mathrm{mg} / \mathrm{dl})$ & $46.1 \pm 30.40$ & $42.4 \pm 140.87$ & 0.942 \\
\hline$\Delta$ Plasma aldosterone (ng/DL) & $-18.2 \pm 28.38$ & $0.5 \pm 22.52$ & 0.077 \\
\hline \multicolumn{4}{|c|}{$\begin{array}{l}\mathrm{DBP}=\text { diastolic blood pressure; } \mathrm{GFR}=\text { glomerular filtration rate; } \mathrm{SBP}=\text { systolic blood pressure; } \Delta \text { makes } \\
\text { reference to the difference between the mean value of the variable in the last visit and the first visit }\end{array}$} \\
\hline
\end{tabular}

\section{Cardiometabolic phenotype of primary aldosteronism's with and without hyperparathyroidism}

Patients with PA and hyperparathyroidism (primary or secondary) presented a similar cardiometabolic profile than patients with normal iPTH levels (Table 3). Similar results were observed when we compared patients with primary hyperparathyroidism $(n=8)$ and the rest of the cohort $(n=36)$. After a median followup of 3.6 years [IQR 1.1-5.9] years, five patients with PA developed one or more new comorbidities (2 new diagnosis of type diabetes, 5 cases of dislipidemia, 2 cardiovascular events and 3 obesity). No differences in the risk of developing new comorbidities was observed between patients with 
hyperparathyroidism and without $(\mathrm{HR}=0.3[0.05-1.91], \mathrm{P}=0.205)$, neither when individual comorbidities were considered $(P>0.05)$. 
Table 3

Description of the comorbidities and the metabolic profile in patients with primary aldosteronism with and without hyperparathyroidism

\begin{tabular}{|c|c|c|c|}
\hline & $\begin{array}{l}\text { Hyperparathyrodism } \\
(\mathrm{n}=29)\end{array}$ & $\begin{array}{l}\text { No hyperparathyrodism } \\
(n=15)\end{array}$ & OR [95\% Cl], P value \\
\hline Age (years) & $55.4 \pm 13.45$ & $54.6 \pm 15.77$ & $\begin{array}{l}O R=1.00[0.96-1.04] \\
P=0.856\end{array}$ \\
\hline Female sex & $51.7 \%(n=15)$ & $46.7 \%(n=7)$ & $\begin{array}{l}\mathrm{OR}=0.82[0.23-2.85] \\
P=0.750\end{array}$ \\
\hline Type 2 diabetes & $10.3 \%(n=3)$ & $33.3 \%(n=5)$ & $\begin{array}{l}\mathrm{OR}=0.23[0.05-1.15] \\
\mathrm{P}=0.068\end{array}$ \\
\hline Dislipidemia & $34.5 \%(n=10)$ & $60.0 \%(n=9)$ & $\begin{array}{l}\mathrm{OR}=0.35[0.10-1.27] \\
P=0.105\end{array}$ \\
\hline Cardiovascular & $25 \%(n=7)$ & $20.0 \%(n=3)$ & $\begin{array}{l}\mathrm{OR}=1.33[0.29-6.14] \\
\mathrm{P}=0.709\end{array}$ \\
\hline Cerebrovascular & $3.6 \%(n=1)$ & $0 \%(n=0)$ & $\mathrm{OR}=\mathrm{NC}, \mathrm{P}=0.629$ \\
\hline CKD & $13.8 \%(n=4)$ & $6.7 \%(n=1)$ & $\begin{array}{l}\mathrm{OR}=2.24[0.23-22.05], \\
P=0.463\end{array}$ \\
\hline Hypokalemia & $41.4 \%(n=12)$ & $28.6 \%(n=4)$ & $\begin{array}{l}\mathrm{OR}=1.76[0.45-6.98] \\
\mathrm{P}=0.411\end{array}$ \\
\hline Obesity & $48.0 \%(n=12)$ & $38.5 \%(n=5)$ & $\begin{array}{l}\mathrm{OR}=1.48[0.38-5.79] \\
\mathrm{P}=0.574\end{array}$ \\
\hline SBP $(\mathrm{mmHg})$ & $145.1 \pm 21.80$ & $133.8 \pm 15.16$ & $\begin{array}{l}\mathrm{OR}=1.03 \text { [0.99-1.08], } \\
\mathrm{P}=0.084\end{array}$ \\
\hline $\mathrm{DBP}(\mathrm{mmHg})$ & $84.4 \pm 9.59$ & $83.2 \pm 11.92$ & $\begin{array}{l}\mathrm{OR}=1.01[0.95-1.08] \\
\mathrm{P}=0.712\end{array}$ \\
\hline Glucose (mg/dl) & $101.2 \pm 18.99$ & $103.8 \pm 25.26$ & $\begin{array}{l}\mathrm{OR}=0.99[0.96-1.02] \\
\mathrm{P}=0.704\end{array}$ \\
\hline GFR (MDRD-4) & $86.9 \pm 26.80$ & $80.9 \pm 19.05$ & $\begin{array}{l}\mathrm{OR}=1.01[0.98-1.03] \\
P=0.442\end{array}$ \\
\hline Sodium (mEq/L) & $141.8 \pm 2.34$ & $141.7 \pm 2.76$ & $\begin{array}{l}\mathrm{OR}=1.01[0.77-1.31] \\
P=0.955\end{array}$ \\
\hline Potassium (mEq/L) & $3.5 \pm 0.59$ & $3.8 \pm 0.63$ & $\begin{array}{l}O R=0.45[0.14-1.42] \\
P=0.157\end{array}$ \\
\hline
\end{tabular}

$\mathrm{CKD}=$ chronic kidney disease; $\mathrm{GFR}=$ glomerular filtration rate (in $\mathrm{ml} / \mathrm{min} / 1.73 \mathrm{~m} 2$ ); OR= odds ratio and $[95 \% \mathrm{Cl}]=95 \%$ confident interval; $\mathrm{PAC}=$ plasma aldosterone concentration; PRA= plasma renin activity. OR were calculated only for categorical variables (by logistic regression model) and $\nabla$ coefficient for continuous variables (by lineal regression model).

*No differences were found in the proportion of patients under lipid lowering medications between the group of hyperparathyroidism and non-hyperparathyroidism (38.1\% vs $33.3 \%, \mathrm{P}=0.784)$ 


\begin{tabular}{|c|c|c|c|}
\hline & $\begin{array}{l}\text { Hyperparathyrodism } \\
(\mathrm{n}=29)\end{array}$ & $\begin{array}{l}\text { No hyperparathyrodism } \\
(n=15)\end{array}$ & OR [95\%Cl], P value \\
\hline Calcium (mg/dl) & $9.2 \pm 0.47$ & $9.5 \pm 0.42$ & $\begin{array}{l}\mathrm{OR}=0.16[0.03-0.88] \\
\mathrm{P}=0.020\end{array}$ \\
\hline $\begin{array}{l}\text { Phosphorus } \\
(\mathrm{mg} / \mathrm{dl})\end{array}$ & $3.2 \pm 0.80$ & $3.5 \pm 0.47$ & $\begin{array}{l}\mathrm{OR}=0.61[0.23-1.60] \\
\mathrm{P}=0.291\end{array}$ \\
\hline ¡PTH (ng/dL) & $98.8 \pm 22.65$ & $48.2 \pm 12.56$ & $P<0.0001$ \\
\hline $\begin{array}{l}250 \mathrm{OH} \text { Vitamin D } \\
(\mathrm{ng} / \mathrm{mL})\end{array}$ & $25.3 \pm 15.32$ & $24.3 \pm 16.33$ & $\begin{array}{l}\mathrm{OR}=1.00[0.96-1.05] \\
\mathrm{P}=0.829\end{array}$ \\
\hline LDL-c (mg/dl) & $108.8 \pm 31.80$ & $125.4 \pm 43.66$ & $\begin{array}{l}O R=0.99[0.97-1.01] \\
P=0.163\end{array}$ \\
\hline HDL-c (mg/dl) & $48.7 \pm 15.68$ & $48.1 \pm 11.95$ & $\begin{array}{l}\mathrm{OR}=1.00[0.96-1.05] \\
\mathrm{P}=0.887\end{array}$ \\
\hline $\begin{array}{l}\text { Triglycerides } \\
(\mathrm{mg} / \mathrm{dl})\end{array}$ & $111.3 \pm 62.74$ & $150.3 \pm 73.64$ & $\begin{array}{l}\mathrm{OR}=0.99[0.98-1.00] \\
P=0.076\end{array}$ \\
\hline PAC (ng/dl) & $32.8 \pm 19.94$ & $46.3 \pm 22.61$ & $\begin{array}{l}\mathrm{OR}=0.97[0.94-1.00] \\
\mathrm{P}=0.054\end{array}$ \\
\hline PRA (ng/ml/h) & $0.6 \pm 0.61$ & $0.7 \pm 0.49$ & $\begin{array}{l}\mathrm{OR}=0.66[0.20-2.16] \\
P=0.485\end{array}$ \\
\hline \multicolumn{4}{|c|}{ 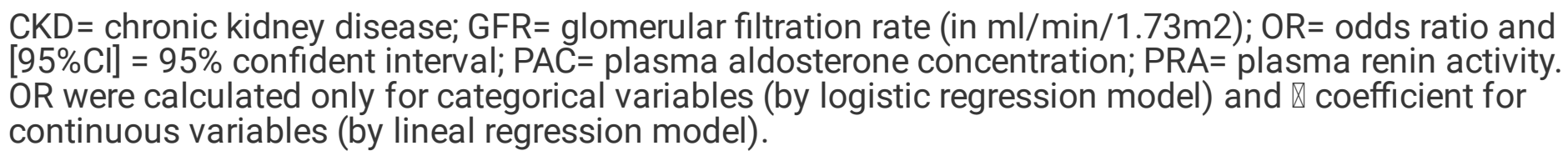 } \\
\hline \multicolumn{4}{|c|}{$\begin{array}{l}\text { *No differences were found in the proportion of patients under lipid lowering medications between the } \\
\text { group of hyperparathyroidism and non-hyperparathyroidism }(38.1 \% \text { vs } 33.3 \%, P=0.784)\end{array}$} \\
\hline
\end{tabular}

\section{Discussion}

In our study we analysed the prevalence of primary (18.2\%) and secondary hyperparathyroidism (47.7\%) in patients with PA and we compared it with its prevalence in EH patients. We found that all the cases of primary hyperparathyroidism in patients with PA were normocalcemic forms. We did nor found differences in the cardiometabolic profile of patients with primary hyperparathyroidism and without in patients with PA.

The prevalence of primary hyperparathyroidism in our series was of $18.2 \%$. This is higher than the reported in previous studies, that described prevalences that varied between $1.2 \%$ and 2.6\% [11][12]. However, it is difficult to know the real prevalence as most of the series were limited to the report of single cases, and the largest series reported included 503 cases of PA, but only 141 patients prospectively included [11]. Nevertheless, the association of PA and primary hyperparathyroidism does not seem to be explained only by chance, as several studies $[4,8,13,20]$ have defended the existence of a bi-directional 
functional link between the adrenocortical zona glomerulosa and the parathyroid gland. In this way, Rossi et al. [22] have demonstrated the expression of the mineralocorticoid receptor in parathyroid adenoma and in normal parathyroid gland tissue, suggesting a role of aldosterone in the regulation of IPTH synthesis and secretion.

We found a prevalence of secondary hyperparathyroidism of $47.7 \%$ in patients with PA. This prevalence was similar that the observed in the $\mathrm{EH}$ cohort, and no differences in $25 \mathrm{OH}$-vitamin D were found between groups. However, several previous studies have observed higher prevalence of secondary hyperparathyroidism in patients with PA than EH patients [11, 23-26]. In this line, Petramala et al. [23] found higher plasma iPTH values in PA patients than in essential hypertensive (EH) and healthy people ( $P<0.001$ and $P<0.001$, respectively), but no differences in serum calcium levels; and Maniero et al. [24] described plasma iPTH levels $31 \%$ greater in PA than in EH patients despite comparable urinary calcium excretion and $25 \mathrm{OH}$-vitamin D insufficiency/deficiency. The finding of higher PTH levels in PA than in EH independently of serum calcium levels was also confirmed by a recent meta-analysis [25]. We cannot exclude that the differences between the findings of our studies and previous reports were related with a selection bias as we only have included patients with evaluation of complete phospho-calcium metabolism that could explained the high prevalence of hyperparathyroidism in both groups and may also reduce the expected differences between groups. Nevertheless, we did not find any correlation between $\mathrm{PTTH}$ and PAC levels neither in PAC between hyperparathyroidism patients, supporting that no differences are expected in PTH levels between PA and EH patients. Other authors have suggested that aldosterone has a stimulatory effect in iPTH [27].

After adrenalectomy vitamin D improved in patients with PA and PTH levels tended to decrease. In this line, previous studies described the correction of hyperaldosteronism after adrenalectomy in patients with aldosterone producing adenoma (APA), and it was associated with an increased in ionized calcium (Ca2 +) and decreased serum iPTH [13][22]. In this way, although the real mechanisms underlying the increase in serum iPTH in PA patients remain to be elucidated, previous studies found that the administration of aldosterone and $1 \% \mathrm{NaCl}$ treatment for 4- 6 weeks to normotensive rats increased $\mathrm{PTTH}$, probably by causing hypercalciuria and thus lowering serum levels of $\mathrm{Ca} 2+[28]$. This outcome can also occur in human PA because of the hyperfiltration-induced calciuretic effect of hyperaldosteronism, which may impact on bone health $[28,29]$. Therefore, the elevated iPTH secretion would represent a compensatory mechanism to the hypercalciuria associated with PA [28][30], that can be reversed after adrenalectomy. Moreover, the interactions between adrenal and parathyroid glands showed differences between patients with upregulated aldosterone production, as in PA, and those with $\mathrm{EH}$ and adrenalectomized patients with APA cured of the hyperaldosteronism. In this context, in patients with PA, the acute inhibition of angiotensin II with captopril had no effect on the overtly elevated iPTH levels [27]. In contrast, captopril lowered serum $\mathrm{iPTH}$ in patients without hyperaldosteronism, including patients with EH and patients with APA biochemically cured by adrenalectomy [27]. These results suggest that the parathyroid gland probably loses its ability to respond to acute angiotensin II inhibition when hyperaldosteronism coexists with increased iPTH secretion [24][22]. These findings are not surprising as angiotensin II is low or suppressed in PA patients due to the indetectable levels of renin, so it is expected that angiotensin II 
inhibition has no effect in patients with PA. However, we could not found an explanation for the observed vitamin $D$ increased after adrenalectomy in our patients, it could be explained by chance as the limited sample size of the adrenalectomy group, so we consider that further studies are needed to elucidate this finding.

We did not observe differences in the cardiometabolic profile of patients with PA regardless of the presence of associated hyperparathyroidism. The increased cardiovascular morbidity and mortality in PA is well established [2]. On the other hand, increased PTH concentration has been shown to represent an independent risk factor for cardiovascular events and cardiovascular mortality with a significant reduction in the associated risk one year following parathyroidectomy [31]. However, there are very few data to evaluate whether the coexistence of both PA and hyperparathyroidism as opposed to PA alone confers an increased cardiovascular morbidity and mortality risk. To our knowledge, only the data from the German Conn's Registry has already addressed this association. Asbach et al. found that there was a non-significant trend towards higher cardiovascular morbidity in patients with PA and secondary hyperparathyroidism. There was a $31.2 \%(n=77)$ cumulative cardiovascular morbidity in patients with PA and secondary hyperparathyroidism vs $21.3 \%(n=61)$ in patients without hyperparathyroidism. The increased cardiovascular risk was mainly driven by the increased prevalence in atrial fibrillation ( $7.8 \mathrm{vs}$ $4.9 \%$ ), acute coronary syndrome (3.9 vs $0 \%$ ) and congestive cardiac failure (11.7 vs $6.6 \%$ ) [11]. This is no surprise, as increased iPTH secretion has been demonstrated in patients with PA possibly due to aldosterone-mediated tubular calcium and magnesium losses [29], with higher iPTH levels in those with the most severe phenotypes, i.e those with APA [11].

The synergistic effect of aldosterone and iPTH increasing the cardiovascular risk was investigated by Tomaschitz et al in a cross-sectional analysis in over 3000 patients referred to coronary angiography in a tertiary center in Germany. Using multivariate Cox proportional hazard analysis, they found that both plasma aldosterone concentration and IPTH were independently associated with cardiovascular mortality, with a synergistic interaction $(P=0.028)$. Indeed, plasma aldosterone concentration and PTH were associated with cardiovascular mortality only in patients in whom both hormones were above the median [32].

There are several limitations in the present study. This is a single-centre, retrospective study, so the information was not always available for comparison. Moreover, the lack of age and renal function matching may play a role as biologically relevant confounding factors. The information about urine calcium excretion was missing in large number of patients. This information could have been interesting as previous studies found increased levels in PA patients compared with EH patients [33][23]. We did not find differences in the prevalence of cardiovascular disease in patients with PA and hyperparathyroidism compared to patients with only PA, although our relatively small sample size might have precluded to find statistically significant differences representing a type 2 statistical error. The same interpretation would apply to the associated risk for chronic kidney disease. Because the catheterization of the adrenal veins was not successful in a majority proportion of patients during the adrenal venous sampling, we could not test whether there were differences in the associated risk with patients with APA and those with idiopathic 
adrenal hyperplasia. Another important aspect that should be investigated is the co-secretion of cortisol in patients with aldosteronomas, since the detrimental effects of excess aldosterone on bone and the alterations of phospo-calcium metabolism might be associated, or at least worsened by the co-secretion of cortisol [34][35]. Furthermore, it will be useful to analyse the impact of this biochemical alterations on bone health.

\section{Conclusions}

Although primary and secondary hyperparathyroidism are common in patients with PA, their prevalence was similar than the observed in EH patients. Primary hyperparathyroidism is usually mild in PA, presenting as normocalcemic forms. No negative implications of the hyperparathyroidism in the cardiometabolic profile of PA were observed.

\section{Declaration}

Financial Support:

SENDIMAD: BECA SENDIMAD de Ayuda a la Investigación en Endocrinología, Nutrición y Diabetes 2019

IRYCIS: Convocatoria intramural de ayudas a proyectos de investigación de investigadores noveles, investigadores clínicos asociados y/o grupos emergentes del Hospital Universitario Ramón y Cajal 2019 Conflict of Interest: The authors have no conflict of interest

Ethical approval: All procedures performed in the participants of the study were in accordance with the ethical standards of the institutional research committee and with the 1964 Helsinki declaration and its later amendments or comparable ethical standards.

\section{References}

1. Araujo-Castro M. [Tratamiento del hiperaldosteronismo primario]. Med Clin (Barc). 2020 Oct 9,155(7):302-308. doi: 10.1016/j.medcli.2020.04.029.

2. De Silva T, Cosentino G, Ganji S, Riera-Gonzalez A, Hsia DS. Endocrine Causes of Hypertension. Curr Hypertens Rep. 2020,22(11):97. doi: 10.1007/s11906-020-01108-3.

3. Tomaschitz A, Ritz E, Pieske B, Fahrleitner-Pammer A, Kienreich K, Horina JH, et al. Aldosterone and parathyroid hormone: A precarious couple for cardiovascular disease. Cardiovasc Res. 2012,94(1):10-9. doi: 10.1093/cvr/cvs092

4. Zheng MH, Li FXZ, Xu F, Lin X, Wang Y, Xu QS, et al. The Interplay Between the Renin-AngiotensinAldosterone System and Parathyroid Hormone. Front Endocrinol (Lausanne). 2020,11:539. doi: 10.3389/fendo.2020.00539. 
5. Kovács L, Góth MI, Szabolcs I, Dohán O, Ferencz A, Szilágyi G. The effect of surgical treatment on secondary hyperaldosteronism and relative hyperinsulinemia in primary hyperparathyroidism. Eur $\mathrm{J}$ Endocrinol. 1998,138(5):543-7. doi: 10.1530/eje.0.1380543

6. Gennari C, Nami R, Gonnelli S. Hypertension and primary hyperparathyroidism: The role of adrenergic and renin-angiotensin-aldosterone systems. Miner Electrolyte Metab. 1995,21(1-3):77-81.

7. Sabbadin C, Cavedon E, Zanon P, lacobone M, Armanini D. Resolution of hypertension and secondary aldosteronismafter surgical treatment of primary hyperparathyroidism. J Endocrinol Invest. 2013,36(8):665-6. doi: 10.3275/8960.

8. Tomaschitz A, Ritz E, Pieske B, Rus-Machan J, Kienreich K, Verheyen N, et al. Aldosterone and parathyroid hormone interactions as mediators of metabolic and cardiovascular disease. Metabolism. 2014,63(1):20-31. doi:10.1016/j.metabol.2013.08.016.

9. Vallumsetla N, Mundi MS, Kennel KA. Secondary hyperparathyroidism. In: Hyperparathyroidism: A Clinical Casebook. 2016. ISBN 978-3-319-25878-2.

10. Corbetta S, Mantovani G, Spada A. Metabolic syndrome in parathyroid diseases. Front Horm Res. 2018,49:67-84. doi: 10.1159/000486003.

11. Asbach E, Bekeran M, König A, Lang K, Hanslik G, Treitl M, et al. Primary and Secondary Hyperparathyroidism in Patients with Primary Aldosteronism - Findings from the German Conn's Registry. Exp Clin Endocrinol Diabetes. 2020,128(4):246-254. doi: 10.1055/a-1027-6472.

12. Concistré A, Petramala L, Zinnamosca L, Settevendemmie A, Corpaci F, Marinelli C, et al. Primary aldosteronism with concurrent primary hyperparathyroidism: Clinical case load in a single centre. Eur Rev Med Pharmacol Sci. 2015,19(6):971-6.

13. Pilz S, Kienreich K, Drechsler C, Ritz E, Fahrleitner-Pammer A, Gaksch M, et al. Hyperparathyroidism in patients with primary aldosteronism: Cross-sectional and interventional data from the GECOH study. J Clin Endocrinol Metab. 2012,97(1):E75-9. doi: 10.1210/jc.2011-2183

14. Ishay A, Herer P, Luboshitzky R. Effects of successful parathyroidectomy on metabolic cardiovascular risk factors in patients with severe primary hyperparathyroidism. Endocr Pract. 2011,17(4):584-90. doi: 10.4158/EP10321.0R.

15. Brunaud L, Germain A, Zarnegar R, Rancier M, Alrasheedi S, Caillard C, et al. Serum aldosterone is correlated positively to parathyroid hormone (PTH) levels in patients with primary hyperparathyroidism. Surgery. 2009,146(6):1035-41. doi: 10.1016/j.surg.2009.09.041.

16. Araujo-Castro M, Bengoa Rojano N, Fernández Argüeso M, Pascual-Corrales E, Jiménez Mendiguchía L, García Cano AM. Cardiometabolic risk in patients with primary aldosteronism and autonomous cortisol secretion. Case-control study. Med Clin (Barc). 2020,S0025-7753(20)30627-8. doi: 10.1016/j.medcli.2020.07.025

17. Classification and diagnosis of diabetes: Standards of medical care in diabetesd2019. Diabetes Care 2019,42:S13-28. https://doi.org/10.2337/dc19-S002.

18. Kjeldsen SE, Narkiewicz K, Burnier M, Oparil S. 2018 Practice guidelines for the management of arterial hypertension of the European Society of Hypertension. Blood Press 2018,27:313. 
https://doi.org/10.1080/08037051.2018.1530564

19. Funder JW, Carey RM, Mantero F, Murad MH, Reincke M, Shibata H, et al. The management of primary aldosteronism: Case detection, diagnosis, and treatment: An endocrine society clinical practice guideline. J Clin Endocrinol Metab. 2016,101(5):1889-916.

20. Silva BC, Cusano NE, Bilezikian JP. Primary hyperparathyroidism. Best Pract Res Clin Endocrinol Metab. 2018,101247. doi: 10.1016/j.beem.2018.09.013.

21. Gómez-Ramírez J, Mihai R. Normocalcaemic primary hyperparathyroidism: a diagnostic and therapeutic algorithm. Langenbeck's Arch Surg 2017,402:1103-8. https://doi.org/10.1007/s00423017-1617-2.

22. Rossi GP, Ragazzo F, Seccia TM, Maniero C, Barisa M, Calò LA, et al. Hyperparathyroidism can be useful in the identification of primary aldosteronism due to aldosterone-producing adenoma. Hypertension. 2012,60(2):431-6. doi: 10.1161/HYPERTENSIONAHA.112.195891

23. Petramala L, Zinnamosca L, Settevendemmie A, Marinelli C, Nardi M, Concistrè A, et al. Bone and mineral metabolism in patients with primary aldosteronism. Int J Endocrinol. 2014,2014:836529. doi: $10.1155 / 2014 / 836529$.

24. Maniero C, Fassina A, Seccia TM, Toniato A, lacobone M, Plebani M, et al. Mild hyperparathyroidism: A novel surgically correctable feature of primary aldosteronism. J Hypertens. 2012,30(2):390-5. doi: 10.1097/HJH.0b013e32834f0451.

25. Shi S, Lu C, Tian H, Ren Y, Chen T. Primary Aldosteronism and Bone Metabolism: A Systematic Review and Meta-Analysis. Front Endocrinol (Lausanne). 2020,11:574151. doi: 10.3389/fendo.2020.574151.

26. Jiang Y, Zhang C, Ye L, Su T, Zhou W, Jiang L, et al. Factors affecting parathyroid hormone levels in different types of primary aldosteronism. Clin Endocrinol (Oxf). 2016,85(2):267-74. doi:

10.1111/cen. 12981

27. Lenzini L, Prisco S, Vanderriele PE, Lerco S, Torresan F, Maiolino G, et al. PTH Modulation by Aldosterone and Angiotensin II is Blunted in Hyperaldosteronism and Rescued by Adrenalectomy. J Clin Endocrinol Metab. 2019,104(9):3726-3734. doi: 10.1210/jc.2019-00143

28. Chhokar VS, Sun Y, Bhattacharya SK, Ahokas RA, Myers LK, Xing Z, et al. Loss of bone minerals and strength in rats with aldosteronism. Am J Physiol Heart Circ Physiol. 2004,287(5):H2023-6. doi: 10.1152/ajpheart.00477.2004.

29. Rossi E, Sani C, Perazzoli F, Casoli MC, Negro A, Dotti C. Alterations of calcium metabolism and of parathyroid function in primary aldosteronism, and their reversal by spironolactone or by surgical removal of aldosterone-producing adenomas. Am J Hypertens. 1995,8(9):884-93. doi: 10.1016/08957061(95)00182-0.

30. Vidal A, Sun Y, Bhattacharya SK, Ahokas RA, Gerling IC, Weber KT. Calcium paradox of aldosteronism and the role of the parathyroid glands. Am J Physiol Heart Circ Physiol. 2006,290(1):H286-94. doi: 10.1152/ajpheart.00535.2005. 
31. Vestergaard P, Mollerup CL, Frøkjær VG, Christiansen P, Blichert-Toft M, Mosekilde L. Cardiovascular events before and after surgery for primary hyperparathyroidism. World J Surg. 2003,27(2):216-22. doi: 10.1007/s00268-002-6541-z.

32. Tomaschitz A, Pilz S, Rus-Machan J, Meinitzer A, Brandenburg VM, Scharnagl H, et al. Interrelated aldosterone and parathyroid hormone mutually modify cardiovascular mortality risk. Int J Cardiol. 2015,184:710-716. doi: 10.1016/j.ijcard.2015.03.062

33. Salcuni AS, Carnevale V, Battista C, Palmieri S, Eller-Vainicher C, Guarnieri V, et al. Primary aldosteronism as a cause of secondary osteoporosis. Eur J Endocrinol. 2017,177(5):431-437. doi: 10.1530/EJE-17-0417 [34] Dubrovsky AMK, Maricic M, Lane NE. Glucocorticoid-Induced Osteoporosis. Contemp. Endocrinol., 2020. https://doi.org/10.1007/978-3-319-69287-6_21.

34. Arlt W, Lang K, Sitch AJ, Dietz AS, Rhayem Y, Bancos I, et al. Steroid metabolome analysis reveals prevalent glucocorticoid excess in primary aldosteronism. JCI Insight. 2017,2(8):e93136. doi: 10.1172/jci.insight.93136. 